Z. klin. Chem. u. klin. Biochem.

8. Jg., S. $477-479$, September 1970

\title{
Automatisierte Magnesium-Mikrobestimmung in biologischem Material mit der Farbstofflösung von MANN und YOE
}

\author{
Von R. Leskovar und Carola leskovar \\ Aus der Balneologischen Forschungsstelle (Ärztlicher Leiter: Prof. Dr. R. Leskovar) des Staatsbades Bad Kissingen
}

(Eingegangen am 28. Mai 1970)

Es wird über zwei Varianten einer Methode zur automatisierten Mg-Bestimmung auf der Grundlage des Farbreagenz nach MANN und YOE berichtet. Mit je $160 \mu l$ Probenmaterial können 40 Bestimmungen pro Stunde durchgefühtt werden.

Bei Variante I wird eine weniger konzentrierte Farbstofflösung verwendet, das biologische Material wird vorher verdünnt, um in den linearen Extinktionsbereich zu gelangen: Serum 1:10, Harn 1:50, Speichel 1:5, Schweiß wurde nach Elution aus Filtrierpapier unverdünnt untersucht.

Variante II ist zur direkten Bestimmung von $\mathrm{Mg}$ im unverdünnten Serum geeignet, wobei sich der lineare Bereich für $1 \mathrm{mg} / 100 \mathrm{~m} / \mathrm{Mg}$ auf 30 Teilstriche der Schreiberpapier-\%-Einteilung erstreckt. Diese Variante weist einen Variationskoeffizienten von 0,88 auf.

Bei 200 Kurpatienten wurden folgende Mg-Werte festgestellt:

$$
\begin{array}{ll}
\text { im Serum } & 2,16 \pm 0,22 \mathrm{mg} / 100 \mathrm{ml} \\
\text { im Speichel } & 0,77 \pm 0,59 \mathrm{mg} / 100 \mathrm{ml} \\
\text { im Schweiß } & 4,36 \pm 2,5 \%, \text { bezogen auf die Summe von } \mathrm{Na}+\mathrm{K}+\mathrm{Ca}+\mathrm{Mg}+\mathrm{Cl}+\mathrm{P}_{1}=100 \% .
\end{array}
$$

The automatic micro-determination of magnesium in biological material with the dye solution of MANN and YOE

Two variants of an automated method for the determination of $\mathrm{Mg}$ based on the colour reagent of MANN and YoE are described. 40 determinations per hour, each requiring a $160 \mu$ l sample, can be performed with either procedure.

In the first procedure a less concentrated dye solution is used and the biological material is first diluted so that the extinction is in the linear range; serum is diluted $1: 10$, urine $1: 50$, saliva $1: 5$, while sweat is eluted from filter paper and used without further dilution.

The second procedure is suitable for the direct determination of $\mathrm{Mg}$ in serum without prior dilution, whereby the linear region for $1 \mathrm{mg} / 100 \mathrm{ml} \mathrm{Mg}$ extends over 30 divisions of the percentage scale on the chart paper. This procedure shows a variation coefficient of 0.88 .

The following $\mathrm{Mg}$ values were determined in 200 patients:

$\begin{array}{ll}\text { serum } & 2.16 \pm 0.22 \mathrm{mg} / 100 \mathrm{~m} l \\ \text { saliva } & 0.77 \pm 0.59 \mathrm{mg} / 100 \mathrm{ml} \\ \text { sweat } & 4.36 \pm 2.5 \% \text { related to the total of } \mathrm{Na}+\mathrm{K}+\mathrm{Ca}+\mathrm{Mg}+\mathrm{Cl}+\mathrm{P}_{\mathrm{i}}=100 \%\end{array}$

Eine Reihe von Methoden zur Magnesium-Bestimmung in Serum bzw. biologischem Material werden wegen verschiedener Mängel nicht einheitlich beurteilt $(1,2)$. Wir selbst waren bei der Durchführung von Reihenuntersuchungen von der komplexometrischen MagnesiumBestimmungsmethode wegen ihrer ungenügenden $\mathrm{Ge}-$ nauigkeit enttäuscht (3). Unterdessen wurde die photometrische Magnesium-Bestimmung mit dem von MANN und YoE verwendeten Farbstoff bekannt und günstig beurteilt (4).

Das Farbreagenz [1-Azo-2-hÿdroxy-3-(2,4-dimethyl-carboxanilido)naphthalin-1 (2-hydroxybenzol-4-natriumsulfonat)] ist im hydro-alkoholischen Milieu bei $\mathrm{pH} 9-10$ blau und bildet mit Magniesium einen rötlichen Komplex. Die entstehende Farbe ist der vorhandenen MagnesiumKonzentration direkt proportional.

Zur Beantwortung balneologischer Fragestellungen über die Rolle des Magnesiums im Elektrolythaushalt im Verlauf von Trinkkuren brauchten wir, um das Magnesium in Serum, Harn, Speichel und Schweiß zu bestimmen, eine automatisierte Methode. Nachdem wir uns von den Vorteilen der manuellen Methode nach MANN und YOE selbst überzeugt hatten, versuchten wir dieses Prinzip zu einer automatisierten Arbeitsweise auszuarbeiten.
Im Verlauf unserer Versuche ${ }^{1}$ ) kamen wir zu zwei Varianten, die sich als brauchbar erwiesen. Der Vorteil der Variante I ist ihre Anwendungsbreite. Verschiedenes biologisches Material kann durch einfache Verdünnung in den Meßbereich gebracht werden (halbautomatisierte Methode). Die Variante II erwies sich zur MagnesiumBestimmung im Serum als geeignet. Serum kommt unverdünnt zur Anwendung.

\section{Methodik}

Geräte

Probennehmer II der Firma Technicon (Autoanalyzer).

Proportionier-Schlauchpumpe der Firma Desaga.

Beckmann DB-Spektrophotometer mit Durchflußküvette, Schichtdicke $10 \mathrm{~mm}$, Extinktionsmaximum $505 \mathrm{~nm}$.

\section{Reagenzien}

Farbreagenz nacb MANN und YOE

Stammlösung: $80 \mathrm{mg}$ 1-Azo-2-hydroxy-3-(2,4-dimethylcarboxanilido)-naphthalin-1-(2-hydroxybenzol-4-natriumsulfonat) (Fa. Merck) werden in $100 \mathrm{~m} /$ absol. Alkohol unter leichtem Erwärmen gelöst. Durch weiteres Verdünnen mit absolutem Alkohol wird die Arbeitslösung für Variante I (1:5) bzw. Variante II (1:2) hergestellt.

1) Bei den Versuchen hat zu Beginn auch unser damaliger Mitarbeiter Dipl.-Chem. H.-G. KöRBrTZ mitgewirkt. 


\section{Natrium-Tetraborat}

$20 \mathrm{~g}$ Natriumtetraborat werden zunächst mit $500 \mathrm{~m} /$ heißem Wasser gelöst, dann auf $1000 \mathrm{ml}$ aufgefüllt.

\section{Magnesium-Standard}

$100 \mathrm{mg}$ Magnesium-Späne werden in etwas $\mathrm{HCl}$ gelöst und dann auf $1000 \mathrm{ml}$ mit Wasser aufgefüllt. Es werden Standardlösungen von 1 bis $10 \mathrm{mg} / 100 \mathrm{~m} /$ Magnesium hergestellt.

\section{Variante I}

Die Pumpenschlauchanordnung ist aus Abbildung 1 ersichtlich. Probennahme 40 pro Std. Verhältnis der Probennahme zur Waschzeit $=1: 2$, Pumpengeschwindigkeit 50. Je Probe werden $151 \mu /$ Material verbraucht. Um in den linear verlaufenden Teil des Extinktionsbereichs zu kommen, 'mußten wir vorher das Serum 1:10, Harn 1:50, Speichel 1:5 verdünnen. Schweiß kam nach Elution unverdünnt zur Untersuchung. Als Arbeitslösung bewährte sich uns eine Verdünnung von 20 Teilen Stammlösung auf 100 Teile absoluten Alkohol. Der 0-Punkt am Photometer wurde auf den Farbreagenz-Leerwert eingestellt. Bei dieser Farbstofflösung erwies sich der Extinktionsbereich zwischen 1 und $3 \mathrm{mg} / 100 \mathrm{~m} /$ als sicher linear und die Eichkurve genügend steil, was eine genauere Serummagnesium-Bestimmung ermöglichte (s. u.).

Bei längerem Arbeiten kann es zum Auskristallisieren von Tetraborat mit Verstopfung enger (Nippel), distaler Leitungsabschnitte kommen. Daher ist eine zwischendurch ausgeführte Durchspülung der abflußnahen Leitungen empfehlenswert.

Variante II

Die Pumpenschlauchanordnung ist aus Abbildung 2 ersichtlich. Die übrige Anordnung ist wie bei Variante I, nur die Arbeitslösung ist konzentrierter: 50 Teile Stammlösung werden auf 100 Teile absoluten Alkohol aufgefüllt. Der 0-Punkt muß stets neu eingestellt werden.

\section{Ergebnisse und Diskussion \\ Variante I}

Die Ergebnisse von Magnesium-Bestimmungen in Serum, Harn, Speichel und Schweiß von je 5 Patienten nach Variante $I$ sind in Abbildung 3 wiedergegeben. Abbildung 4 zeigt 12 Serumbestimmungen (mit Schreiber-Skalenspreizung 1:2). Sie wurden zweimal durchgeführt, wobei die Schreibertrommel so zurückgedreht wurde, daß der zweite Wert parallel zu dem der Erstbestimmung lag. Das erleichtert die Berechnung des Mittelwerts. Der erste Serumwert, der dem MagnesiumStandard folgt, erweist sich immer als zu niedrig. Es empfiehlt sich daher, einer Serum-Untersuchungsserie ein "Leerserum" vorzuschalten.

Vergleicht man die Standards $1 \mathrm{mg}, 2$ und $3 \mathrm{mg} / 100 \mathrm{ml}$ - sie müssen verständlicherweise ebenfalls 1:10 weiter verdünnt werden - so verläuft die Eichkurve zwischen 1 bis $3 \mathrm{mg} / 100 \mathrm{ml}$ linear, während die Werte von $0-1 \mathrm{mg} / 100 \mathrm{~m} l$ zu hoch sind.

Der genaue Serummagnesiumwert kann aus den Kurven leicht errechnet werden: Der Serum-Magnesiumwert setzt sich zusammen aus $1 \mathrm{mg} / 100 \mathrm{~m} /$ Magnesium und einem Restwert, der jedoch von Serum zu Serum variiert. Dieser $z$ wischen 1 und $3 \mathrm{mg} / 100 \mathrm{~m} l$ liegende Restwert wird mit einem für diesen Bereich gültigen Faktor errechnet und dann zu $1 \mathrm{mg} / 100 \mathrm{~m} l$ Magnesium addiert. Der Serum-Magnesiumwert ist also $1+$ Serumrestwert $\times$ Faktor. In dieser Anordnung machte die Differenz zwischen $1-3 \mathrm{mg} / 100 \mathrm{ml}$ eine Höhe von 8 Linien des

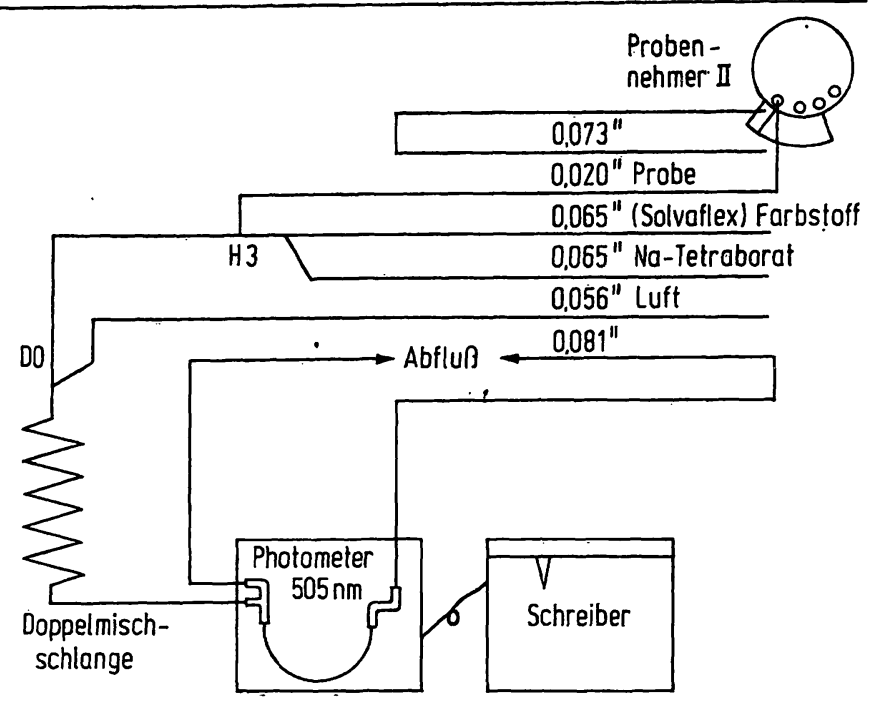

Abb. 1

Fließdiagramm Magnesium nach Variante I

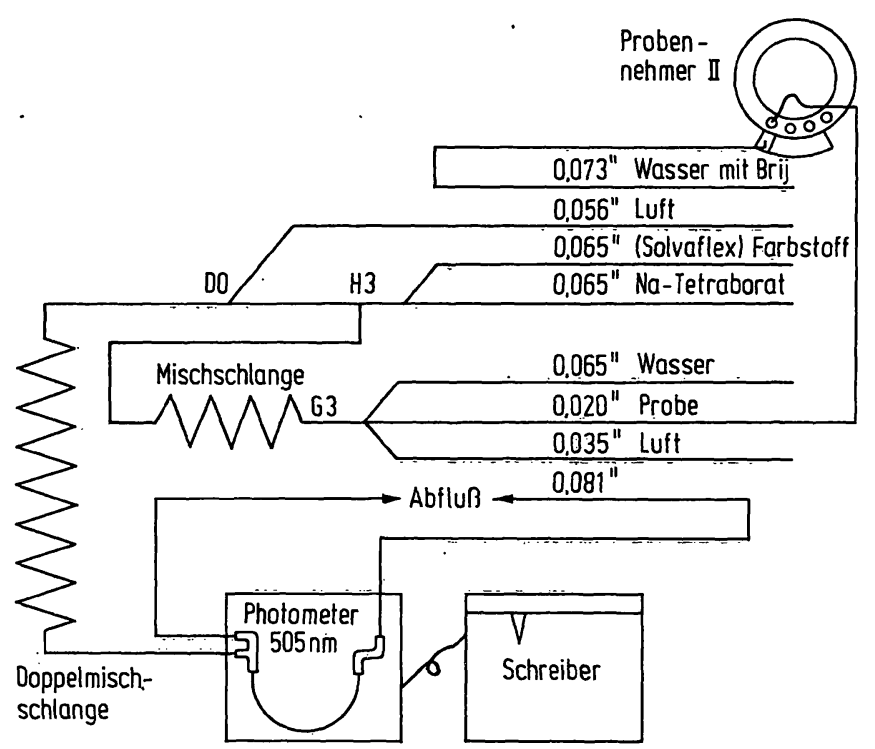

Abb. 2

Fließdiagramm Magnesium nach Variante II

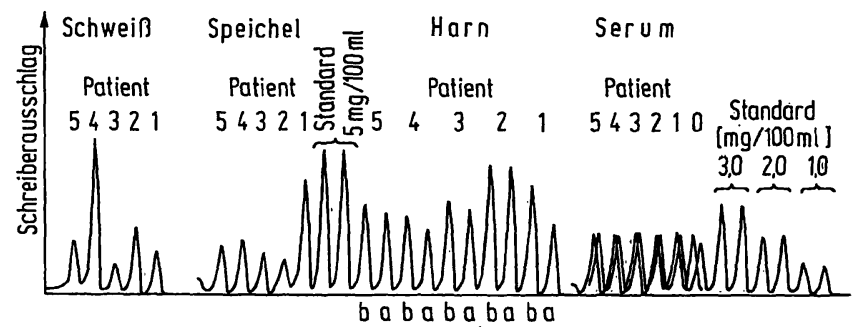
Abb. $3^{-}$

Magnesiumbestimmungen in Serum $(0=$,Leerserum"), Harn ( $a=$ unbehandelt, $\mathrm{b}=$ angesäuert), Speichel und Schweiß nach Variante I bei je 5 Patienten. Serum vorher $1: 10$, Harn $1: 50$ und Speichel $1: 5$ verdünnt. Beim SchweiB handelt es sich um wäßr. Eluat. Die 2. Bestimmung des Serummagnesiums wird durch Rückdrehen der Schreibertrommel unmittelbar hinter die 1. Bestimmung gebracht

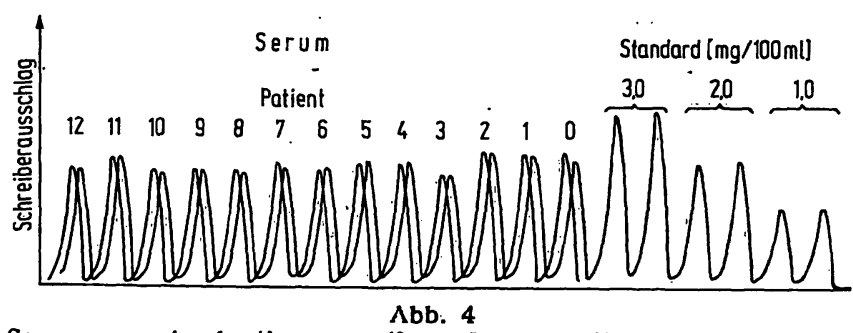

Serummagnesiumbestimmung $(0 \approx$, Leerserum" $)$ nach Variante I (lineare Schreibung mit Skalenspreizung.1:2) 
Schreiberpapiers aus. Einem Linienabstand entsprachen somit $0,25 \mathrm{mg} / 100 \mathrm{ml}$ Magnesium. Da sich ein Linienabstand durch Abschätzung leicht vierteilen läßt, ergibt das eine weitere Genauigkeitssteigerung von $0,06 \mathrm{mg} / 100 \mathrm{~m} / \mathrm{Magnesium}$. Doppelbestimmungen steigern die Genauigkeit.

Die Magnesium-Bestimmung als solche erwies sich als sehr genau. 61 Bestimmungen desselben Serums ergaben einen Mittelwert von $2,11 \mathrm{mg} / 100 \mathrm{~m} /$ mit einer Standardabweichung von 0,023 , was einen Variationskoeffizienten $\operatorname{von} \frac{s \cdot 100}{x}=V=\frac{2,3}{2,11}=>1$ ergibt. Diese Genauigkeit wird durch den Pipettierfehler im Verlauf der Bereitung von Verdünnungen beeinträchtigt. Eine Überprüfung dieses Fehlers auf Grund von 20 Verdünnungen desselben Serums 1:10 mit Hilfe der MikroliterPipetten Marburg durchgeführt, ergab einen Mittelwert $\bar{x}=2,067 \mathrm{mg} / 100 \mathrm{ml}$, eine Standardabweichung von 0,075 und einen Variationskoeffizienten von 3,64\%.

Magnesium-Bestimmungen im Serum von $200 \mathrm{Kurpa-}$ tienten ergaben einen Mittelwert $\overline{\mathrm{x}}=2,15 \pm 0,22 \mathrm{mg} /$ $100 \mathrm{ml}$.

Verglichen mit Magnesium-Werten des Standardserums Monitrol der Firma Dade zeigten unsere Seren, die wir auf die wäßrigen Standards bezogen, niedrigere Werte.

\section{Magnesium-Bestimmungen im Harn}

$\mathrm{Um}$ in den linearen Extinktionsbereich zu kommen, wurde der Harn 1:50 verdünnt. Ein Teil des Magnesiums im Harn ist als $\mathrm{NH}_{4} \mathrm{MgPO}_{4}$ gebunden und läßt sich erst bestimmen, wenn der Harn zunächst auf ein $\mathrm{pH}$ von 3-4 gebracht wird. Das erreicht man durch Zugabe von $1-2$ Tropfen $0,1 \mathrm{~N} \mathrm{HCl}$ zur Verdünnung. In $\mathrm{Ab}$ bildung 3 ist vom selben Harn eine Magnesium-Bestimmung nach Verdünnung mit dest. Wasser und anschließend nach Zugabe von 1 Tropfen $0,1 \mathrm{~N} \mathrm{HCl}$ dargestellt. Das gebundene Magnesium im Harn kann somit hoch sein.

Sollte trotz Verdünnung die Magnesium-Konzentration im Harn hohe Spitzen in der Kurvenschreibung ergeben, die den linearen Bereich der Eichkurve zu überschreiten scheint, so kann ohne wesentlichen Zeitverlust ein entsprechender Standard "nachgeschickt" werden (vgl. Harn in Abb. 3).

Für das Harn-Magnesium werden keine UntersuchungsResultate angeführt, da wir nur Einzelproben unter. suchten und keine Tagesausscheidung bestimmten.

\section{Magnesium-Bestimmungen im Speichel}

Der Speichel wurde durch Lutschen von Paraffinplätzchen und Entleeren des so gebildeten Speichels in ein Reagenzglas gewonnen. Eindickung des Speichels durch Verdunsten konnte nicht völlig ausgeschlossen werden. Darüberhinaus schwankten die Werte bei unseren Patienten sehr stark. Zur Magnesium-Bestimmung verdünnten wir den Speichel 1:5.

Bei 200 Kurpatienten wurde zu Kurbeginn im Speichel ein Magnesium-Mittelwert von $0,768 \pm 0,592 \mathrm{mg} / 100$ festgestellt.
Magnesium-Bestimmungen im Schweiß

Patienten werden einer schweißtreibenden Wärmebehandlung, z. B. Moor- oder Paraffinpackung, unterworfen, wobei ihnen ein Filterpapierstreifen an der Stirn bcfestigt wurde. Dieser Filterstreifen wurde sachgemäß behandelt, um nicht zu falschen Werten zu kommen, und zuletzt mit siedendem demineral. Wasser eluiert, das Eluat auf den Elektrolytgehalt (Natrium, Kalium, Calcium, Magnesium, Chlorid, Phosphat) ${ }^{2}$ ) untersucht. Die gefundenen Werte wurden als Prozentgebalt, bezogen auf die Summe obiger Elektrolyte, ausgewertet.

Bci 67 Patienten betrug der Mittelwert $=4,36 \pm 2,5 \%$.

\section{Variante II}

Die Magnesium-Bestimmung im Serum kann mit der Pumpenschlauchanordnung, die aus Abbildung 2 ersichtlich ist, direkt ohne Serumverdünnung erfolgen. Úbrige Bedingungen der Anordnung wie bei Variante I.

Abbildung 5 zeigt den großen Meßbereich zwischen 1 und $3 \mathrm{mg} / 100 \mathrm{ml}$, in dem die Eichkurve linear verläuft. Der Bereich der Serumwerte ist durch jeweils um $0,2 \mathrm{mg} / 100 \mathrm{~m} /$ gesteigerte Standards - von 1,0 bis $3,0 \mathrm{mg} / 100 \mathrm{ml}$ gut sichtbar. Der Abstand zweier \%Teillinien des Schreiberpapiers entspricht $0,033 \mathrm{mg} /$ $100 \mathrm{~m} / \mathrm{Mg}$, d. h. der Abstand dreier Linien des Schreiberpapiers macht erst eine Einheit der 1. Dezimale aus. 50 Bestimmungen desselben Serums nach dieser Methode ergaben einen Mittelwert von 2,0236 $\pm 0,0178 \mathrm{mg} / 100 \mathrm{~m} /$. Das ergibt einen Variationskoeffizienten von $0,88 \%$.

2) In weiteren Untersuchungen auch Sulfat.

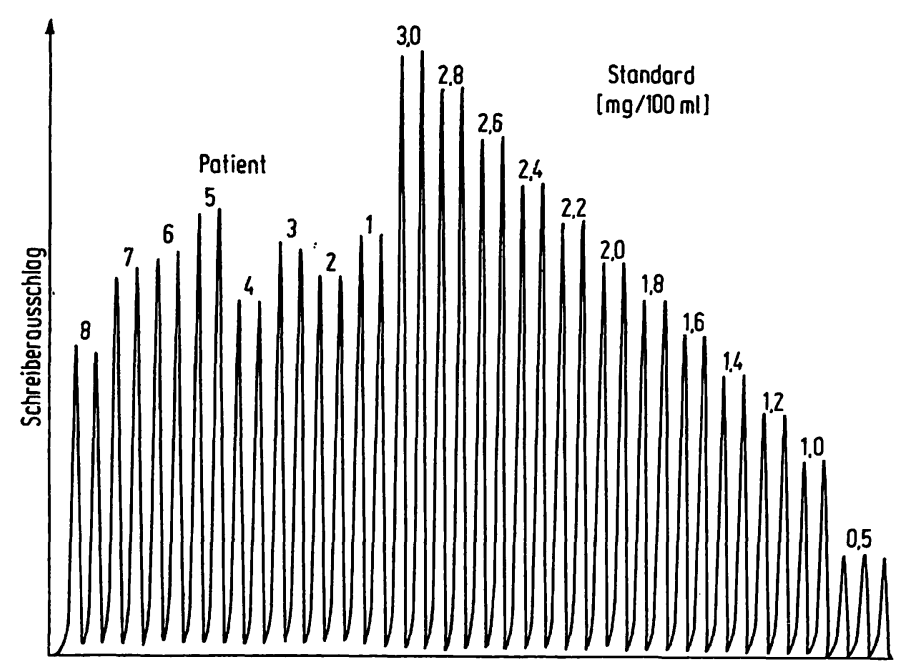

Abb. 5

Magnesiumbestimmung nach Variante II. Rechts 3 Standards von $0,5 \mathrm{mg} / 100 \mathrm{ml}$, dann je 2 Standards mit steigender Konzentration von 1,0 bis $3,0 \mathrm{mg} / 100 \mathrm{ml} \mathrm{Mg}$. Anschließend Doppelwerte für Serummagnesium bei 8 Patienten (logarithmische Schreibung)

\section{Literatur}

1. Ruchterich, R., Klinische Chemic. Akad. Verlagsgesellschaft Frankfurt a. M. (1965). - 2. Simon, K. H., Magnesium. Physiologie. Pharmakologie. Klinik. Wissenschaftl. Verlagsgesellschaft Stuttgart (1967). - 3. Leskovar, R., Zschr. angew. Bäder- u. Klimaheilk. 15, 246 (1968). - 4. Boiruon, C., Clin. Chim. Acta (Amsterdam) 7, 811-817 (1962).

Prof. Dr. R. Leskovar 8730 Bad Kissingen/Hausen Balncologische Forschungsstelle 